\title{
Patient Referral
}

\author{
John Snowden and Rafael F. Duarte
}

Early and efficient patient referral is a critical step in the ability of potential candidates to access CAR-T therapy. Despite improvements in centre qualification and availability, regulatory and reimbursement frameworks, and addressing the educational needs of the various members of the health care team, referring haematologists and oncologists identify major barriers to prescribing CAR-T therapy, including cumbersome logistics, high cost and toxicity, and clinical challenges, such as deterioration of the patient prior to CAR-T administration and the need for bridging chemotherapy while awaiting manufacturing (Chavarría 2021).

Pathways for referral vary between countries and regions, but generally, patients are referred to the regional CAR-T specialist multidisciplinary team (MDT) according to agreed pathways, which in turn, may be linked with national committees often necessary for additional clinical support and/or to confirm funding. These specialist MDTs confirm patient eligibility in line with the manufacturer's licence and based on diagnosis, age, fitness, disease, and treatment stage. Thereafter, the CAR-T centres will arrange to assess the patient directly (with their carers) and provide detailed information enabling the patient to understand the potential benefits, risks, and complications of treatment and to provide informed consent.

Irrespective of the treatment site, clinicians must consider the eligibility of potential patients for CAR-T cells at an early stage so that strategic decisions can be made regarding the best therapeutic pathway. Eligibility should be directly confirmed with regard to age, fitness, disease, and treatment stage. In addition, referring

\footnotetext{
J. Snowden $(\triangle)$

Department of Haematology, Sheffield Teaching Hospitals NHS Foundation Trust and University of Sheffield, Sheffield, UK

e-mail: john.snowden1@nhs.net

R. F. Duarte

Department of Hematology, Hospital Universitario Puerta de Hierro Majadahonda and Universidad Autónoma de Madrid, Madrid, Spain

e-mail: rafael.duarte@ salud.madrid.org 
clinicians should inform their patients of the potential of using CAR-T cells in their treatment early in the pathway, especially if treatment may take place in another centre some distance from their home or base centre (Gajra et al. 2020). In addition to confirmation of eligibility and logistical arrangements with the treatment site, prompt referral and good communication are also desirable to plan the salvage protocol for bridging CAR-T therapy, particularly because defined recovery periods may be required before leukapheresis and the quality of circulating T-cells may decrease with increasing chemotherapy exposure. Sometimes patients without a high peripheral disease burden and sufficient circulating T-cells (e.g., total lymphocyte count of $>0.5 \times 10^{9} / \mathrm{L}$ or a peripheral blood CD3 count of $>150$ per $\mu \mathrm{l}$ ) may be able to undergo leukapheresis for CAR-T cells before starting salvage therapy for relapse. For other patients, planning bridging therapy with the CAR-T therapy centre will be necessary. Therapies likely to significantly impair lymphocyte number and/or function should be avoided to allow successful leukapheresis for CAR-T cell therapy. Therefore, careful scheduling and prioritization of patients is required, including planning for leukapheresis, particularly given that CAR-T manufacture can take over one month. Finally, capacity planning is required for subsequent stages of care in the CAR-T centre, and later, shared care arrangements will enable continuity of care after a patient returns home (Maus and Levine 1996).

\section{Key Points}

- Prompt early patient referral from the base hospital to the treatment centre facilitates various aspects of the planning for CAR-T therapy.

- The learning curve in the CAR-T therapy framework will also inform and facilitate the management and referral of patients for other advanced therapy medicinal products.

\section{References}

Chavarría T. Real-world regulatory issues in the implementation of advanced therapies. Multistakeholder forum at 47th EBMT annual meeting. 2021. Available at www.ebmt.org

Gajra A, Jeune-Smith Y, Kish J, Yeh T-C, Hime S, Feinberg B. Perceptions of community hematologists/oncologists on barriers to chimeric antigen receptor T-cell therapy for the treatment of diffuse large B-cell lymphoma. Immunotherapy. 2020;12(10):725-32. https://doi.org/10.2217/ imt-2020-0118.

Maus MV, Levine BL. Chimeric antigen receptor T-cell therapy for the community oncologist. Oncologist. 1996;21:608-17. https://doi.org/10.1634/theoncologist.2015-0421. 
Open Access This chapter is licensed under the terms of the Creative Commons Attribution 4.0 International License (http://creativecommons.org/licenses/by/4.0/), which permits use, sharing, adaptation, distribution and reproduction in any medium or format, as long as you give appropriate credit to the original author(s) and the source, provide a link to the Creative Commons license and indicate if changes were made.

The images or other third party material in this chapter are included in the chapter's Creative Commons license, unless indicated otherwise in a credit line to the material. If material is not included in the chapter's Creative Commons license and your intended use is not permitted by statutory regulation or exceeds the permitted use, you will need to obtain permission directly from the copyright holder.

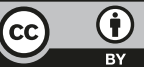

